\title{
Revisión legal y jurisprudencial del fuero de personas con discapacidad física, psíquica o sensorial
}

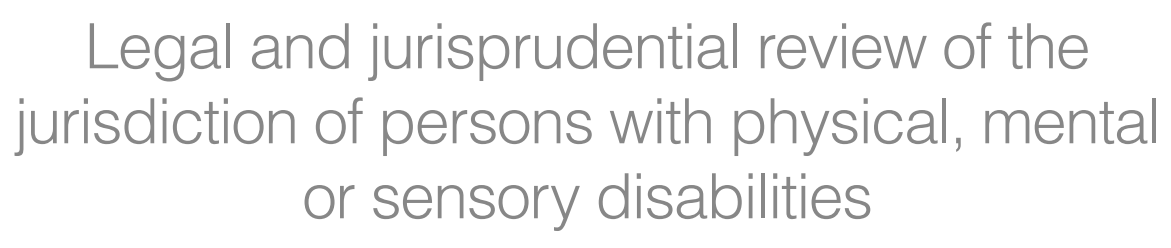

Luz Mery Rodríguez Lascarro'

1 Magíster de la Universidad del Norte en Derecho laboral. Correo electrónico: luzrodriguez@mail.uniatlantico.edu.co

\section{RESUMEN}

El artículo 53 de nuestra Constitución actual, consagra unos principios mínimos fundamentales, que deberán estar siempre presentes en las relaciones laborales, con el fin de brindar protección y superiores garantías a los trabajadores, esto acompañado de la expedición de jurisprudencia garantista por parte de la Corte Constitucional, quien al resolver los casos que por tutela deben ser sometidos a esa corporación para su eventual revisión. Entre los principios allí consagrados, encontramos el de "estabilidad en el empleo", (Valencia, 2007, p. 220) del cual de acuerdo a las necesidades en materia laboral se han creado los llamados fueros de protección laboral, blindando al trabajador que por encontrarse en un estado de debilidad manifiesta no poder ser despedido sin el cumplimiento previo de un trámite especial para que proceda su desvinculación laboral.

De allí surge el de "La estabilidad laboral reforzada o fuero de personas con discapacidad física, psíquica y sensorial," es un beneficio que tienen los trabajadores que por su situación de salud, se encuentran en estado de debilidad manifiesta o vulnerabilidad y que evita que puedan ser despedidos sin que sea agotado el debido proceso, en este caso el permiso de la autoridad competente en lo laboral como es el inspector del trabajo, pues de lo contrario se considera que el despido es ineficaz.

Palabras clave: Discapacidad, empleo, estabilidad y fuero.

\section{ABSTRACT}

Article 53 of our current Constitution enshrines fundamental minimum principles, which must always be present in labor relations, in order to provide protection and greater guarantees to workers, accompanied by the issuance of judicial guarantees by the Court Constitutional, who in resolving the cases that by tutela must be submitted to that corporation for its eventual revision. Among the principles enshrined there is that of "stability in employment", which according to the needs in labor matters have been created so-called labor protection courts, shielding the worker who because he is in a state of manifest weakness cannot be dismissed without the previous fulfillment of a special procedure for their dismissal.

Hence emerges the one of "The reinforced labor stability or jurisdiction of people with physical disabilities, psychic and sensory", is a benefit for workers because of their health situation, they are in state of weakness or vulnerability and that prevents them from being dismissed without due process, in this case with the permission of the competent authority in labor matters as the labor inspector, otherwise that dismissal is considered ineffective.

Keywords: Disability, work, stability, and jurisdiction.
Recibido: 01-08-17 Aceptado: 01-09-17 Publicado: 18-01-18 


\section{INTRODUCCIÓN}

Desde la Constitución Política de 1886, el artículo 17 consagraba una protección especial para el trabajo, contenida en el siguiente texto: "El trabajo es una obligación social y gozará de la especial protección del Estado" (Cañón, 2013, p. 18). A partir de este mandato, se han ido estableciendo en Colombia, diversas formas de protección para la población vinculada al trabajo formal de carácter subordinado, entre las que podemos mencionar la estabilidad laboral reforzada de personas con discapacidad física, psíquica o sensorial que es el tema que se tocará en el presente trabajo.

Con la expedición de la Constitución Política de 1991, Colombia entra en la era del constitucionalismo del derecho del trabajo, es decir, le da un tratamiento especial a diferencia de la parquedad con que de este se ocupó la Constitución anterior. Esta Constitución da un vuelco a la normativa constitucional existente sobre la cuestión laboral (C. Const., Sala Plena, Sentencia T-462/92, M.P. Gloria Stella Ortiz Delgado), "elevando al trabajo a rango de postulado ético-político necesario para la interpretación (Zagrebelsky, 1995), de la acción estatal y de los demás derechos y deberes incluidos en la Carta, así como factor indispensable de integración social" (Villegas, 2016, p. 11), es así como surge la redacción del artículo $2^{\circ}$ que establece su condición de principio fundante de la organización social, el artículo 25 lo cataloga como derecho fundamental y el artículo 53 determina los principios mínimos que deben observarse en el marco de las relaciones laborales, uno de ellos la estabilidad en el empleo (C. Const. Sentencia T-141/16, M.P. Alejandro Linares), el cual es una manifestación del principio de seguridad, consistente en la garantía que debe tener cada trabajador, para permanecer en el mismo empleo, mientras no genere motivos para ser desvinculado por cualquiera de las causales previstas como justificadas (C. Const. Sentencia T-141/16, M.P. Alejandro Linares, p. 12), el artículo 54, dicta que es obligación del Estado y de los empleadores ofrecer formación y habilitación profesional y técnica a quienes lo requieran.

Es obligación especial del Estado, propiciar la ubicación laboral de las personas en edad de trabajar y garantizar a los minusválidos el derecho a un trabajo acorde con sus condiciones de salud y finalmente, el artículo 68 en el último inciso precisa que se debe erradicar el analfabetismo y se deberá propiciar la educación de personas con limitaciones físicas o mentales, o con capacidades excepcionales. En el mismo sentido, el artículo 9 del Código Sustantivo del Trabajo, establece que el trabajo goza de la protección del Estado. 
Por su parte la estabilidad laboral reforzada (Dueñas, 2012, p. 3) es la protección constitucional que se deriva de un fuero y es el empleador quien tiene la carga procesal resultado del principio de solidaridad, de continuar el vínculo laboral de manera independiente al tipo de contrato; para dar por terminado el contrato de trabajo deberá contar con el permiso del inspector del trabajo para terminar o hacer efectiva su culminación (Méndez, 2016, p. 146).

En el presente trabajo se abordará el tema de la estabilidad laboral reforzada o fuero de personas con discapacidad física, psíquica o sensorial, para explicar en un solo texto en qué casos se aplica, a qué tipo de beneficios puede tener derecho el trabajador con algún tipo de las discapacidades mencionadas, por lo que la metodología del artículo será la de un artículo de revisión de acuerdo a la clasificación de Colciencias, recogiendo en un solo texto, leyes, decretos, jurisprudencia (especialmente de la Corte Constitucional), tratados y convenios internacionales ratificados por Colombia que hacen referencia al tema y que por esta razón son parte de la legislación interna.

Inicialmente se hace mención ordenada de los decretos que consagran este fuero como son el Decreto 2351 de 1965, Art. 16, numeral 1ํ, seguido del Decreto 2177 de 1989, artículos 16 y 17, por el cual se desarrolla la Ley 82 de 1988, aprobatoria del Convenio Número 159, suscrito con la Organización Internacional del Trabajo, sobre readaptación profesional y el empleo de personas inválidas, en sus artículos 16 y 17; la Ley 361 de 1997, Art. 26, modificado por el Art. 137; el Decreto Nacional 019 de 2012; la Ley 776 de 2002, Art. 8; convenios y tratados internacionales ratificados por Colombia y que por tal razón hacen parte de la legislación interna, como la Convención Americana para la eliminación de todas las formas de discriminación contra las personas con discapacidad, y que fuera aprobada por nuestro legislador por la Ley 1346 de 2009 y alguna jurisprudencia emanada especialmente por la Corte Constitucional, entre las que se exponen la C-531 de 2000, C-710 de 1996, T-462 de 1992, SU-256 de 1996, T-1040 de 2001, T-309 de 2005, SU-388 de 2005, T-661 de 2006, T-687 de 2006, T-1046 de 2008, T-337 de 2009, T-057 de 2016 y T-141 de 2016, entre otras.

\section{ESTABILIDAD EN EL EMPLEO}

Robert Alexy (2007) en su Teoría de los derechos fundamentales, refiriéndose a la amplitud del concepto de principio, predica que los principios pueden referirse tanto a derechos individuales como a bienes colectivos. En este caso la estabilidad en el empleo es un principio mínimo fundamental del derecho 
del trabajo, consistente en la garantía que debe tener cada trabajador para permanecer en el mismo empleo, mientras no genere motivos para ser desvinculado por cualquiera de las causales previstas como justificadas en el Código Sustantivo del Trabajo.

Los principios generales del derecho del trabajo, son las reglas inmutables e ideas esenciales que forman las bases en las cuales se sustenta todo el ordenamiento jurídico laboral [...] Tienen ellos cuatro funciones esenciales: 1) Orientadora e informadora... 2) Normativa e integrativa... 3) Interpretadora...4) Unificante o de armonización de política legislativa y judicial (Grisolia, 2002, p. 51).

Para activarla como principio garantista, la estabilidad laboral debe estar revestida de dos presupuestos básicos: objetivo y subjetivo. Por el presupuesto objetivo, existe la seguridad que están dadas las condiciones empresariales y contextuales para que el trabajador permanezca en el trabajo en cuanto tiene funciones definidas y está garantizada su remuneración en las condiciones estipuladas; "por el presupuesto subjetivo, el trabajador abriga la convicción personal o certidumbre de que, mientras se cumpla con las condiciones estipuladas, además de las previstas en la ley, no será removido de su trabajo" (Vanegas, 2007, p. 321).

La Corte Constitucional, mediante Sentencia SU-250 de 1998 (M.P. Alejandro Martínez Caballero), explica que no siempre el derecho al trabajo se confunde con la estabilidad absoluta. Expresa que frente a la estabilidad laboral, existen variadas caracterizaciones: desde la estabilidad impropia (pago de indemnización) y la estabilidad laboral "precaria" (caso de los empleados de libre nombramiento y remoción que pueden ser retirados en ejercicio de un alto grado de discrecionalidad), hasta la estabilidad laboral absoluta (reintegro derivado de considerar nulo el despido).

\section{ESTABILIDAD LABORAL REFORZADA DESDE LA PROTECCIÓN DE LA} SALUD

De acuerdo a lo expresado por el exmagistrado de la Corte Constitucional (Sentencia 531/00, M.P. Álvaro Tafur Galvis), la jurisprudencia emanada de la Sala Plena de esta máxima corporación ha evolucionado en etapas (Cepeda, 2008, p. 127), y en la tercera etapa que va desde el año 2001 al 2003, emitió la Sentencia C-531 de 2000, para pronunciarse sobre la constitucionalidad parcial del artículo 26 de la Ley 361 de 1997, en la frase contenida en el primer 
párrafo y la totalidad del texto del inciso segundo de la norma, las cuales transcribimos textualmente a continuación:

salvo que medie autorización de la Oficina de Trabajo. No obstante, quienes fueren despedidos o su contrato terminado por razón de su limitación, sin el cumplimiento del requisito previsto en el inciso anterior, tendrán derecho a una indemnización equivalente a ciento ochenta días del salario, sin perjuicio de las demás prestaciones e indemnizaciones a que hubiere lugar de acuerdo con el Código Sustantivo del Trabajo y demás normas que lo modifiquen, adicionen, complementen o aclaren.

En esta oportunidad, resolvió la Corte Constitucional declarar exequible tanto la frase antes anotada como el inciso segundo del artículo 26 de la Ley 361 de 1997, pero con respecto al inciso aclaró que lo hacía bajo el supuesto de los términos de esa providencia y debido a los principios de respeto a la dignidad humana, solidaridad e igualdad contenidos en los artículos $2^{\circ}$ y 13 constitucionales en favor de los disminuidos físicos, sensoriales y síquicos, en este punto dando alcance a los artículos 47 y 54 , ya que carece de todo efecto jurídico el despido o la terminación del contrato de una persona por razón de su limitación sin que exista autorización previa de la Oficina de Trabajo que constate la configuración de la existencia de una justa causa para el despido o terminación del respectivo contrato.

Es una prerrogativa de ciertos trabajadores que, por estar en una situación especial prevista en la ley, cuentan con la opción de conservar el empleo, al punto de no poder ser despedidos sin autorización de la autoridad competente, en el entendido de que "el permiso que otorga el inspector del trabajo, si bien se constituye en una presunción de la existencia de un despido justo, es una presunción legal que puede ser desvirtuada ante el juez correspondiente" (C. Const. Sentencia C-710/96, M.P. Jorge Arango Mejía), cuando son despojados de su trabajo sin dicha autorización o de otra manera irregular, el despido se considera ineficaz y el empleador puede verse abocado a reintegrarlos por orden judicial, sin perjuicio de las remuneraciones salariales causadas, brindándoles una igualdad real y efectiva en materia laboral.

\section{SUJETOS AMPARADOS POR EL FUERO DE ESTABILIDAD LABORAL REFORZADA}

Entre algunos de los sujetos que gozan de esta protección especial, se pueden mencionar a los discapacitados, los minusválidos, las mujeres embara- 
zadas, los enfermos de $\mathrm{VIH}$, madres y padres cabeza de familia (Sentencia SU-256/96, M.P. Vladimiro Naranjo Mesa).

Derecho a la estabilidad laboral reforzada en la legislación actual:

Decreto 2351 de 1965, Art. 16, numeral $1^{\circ}$, en este decreto se contempla la obligación, de parte de los empleadores, de reinstalar a los trabajadores en los cargos que venían desempeñando, siempre y cuando recuperen su capacidad de trabajo. La existencia de una incapacidad parcial no será impedimento para su reinstalación, si los diagnósticos médicos determinan que el trabajador puede seguir realizando el trabajo:

1. A proporcionar a los trabajadores incapacitados parcialmente un trabajo compatible con sus aptitudes, para lo cual deberán efectuar los movimientos de personal que sean necesarios.

2. El incumplimiento de estas disposiciones se considerará como un despido injustificado.

El Decreto 2177 de 1989, artículos 16 y 17, por el cual se desarrolla la Ley 82 de 1988, aprobatoria del Convenio número 159, suscrito con la Organización Internacional del Trabajo, sobre readaptación profesional y el empleo de personas inválidas, en sus artículos 16 y 17, reza:

Artículo 16. Todos los patronos públicos o privados están obligados a reincorporar a los trabajadores inválidos, en los cargos que desempeñaban antes de producirse la invalidez si recupera su capacidad de trabajo, en los términos del Código Sustantivo del Trabajo. La existencia de una incapacidad permanente parcial no será obstáculo para la reincorporación, si los dictámenes médicos determinan que el trabajador puede continuar desempeñándolo.

Artículo 17. A los trabajadores de los sectores público y privado que, según concepto de la seguridad competente de salud ocupacional o quien haga las veces en la respectiva entidad de seguridad o previsión social o medicina del trabajo, en caso de no existir afiliación a dichas instituciones, se encuentren en estado de invalidez física, sensorial o mental, para desempeñar las funciones propias del empleo de que sean titulares del empleo y la incapacidad no origine el reconocimiento de pensión de invalidez, se les deberán asignar funciones acordes con el tipo de limitación o trasladarlos a cargos que tengan la misma remuneración, siempre y cuando la incapacidad no impida el cumpli- 
miento de las nuevas funciones ni impliquen riesgo para su integridad.

(Sentencia T-1046/08, M.P. Dr. Mauricio González Cuervo)

La Ley 361 de 1997, Art. 26, modificado por el Art. 137, Decreto Nacional 019 de 2012, establece que en ningún caso la limitación de una persona, podrá ser motivo para obstaculizar una vinculación laboral, a menos que dicha limitación sea claramente demostrada como incompatible e insuperable en el cargo que se va a desempeñar. Así mismo, ninguna persona limitada podrá ser despedida o su contrato terminado por razón de su limitación, salvo que medie autorización de la Oficina de Trabajo.

No obstante, quienes fueren despedidos o su contrato terminado por razón de su limitación, sin el cumplimiento del requisito previsto en el inciso anterior, tendrán derecho a una indemnización equivalente a ciento ochenta días del salario, sin perjuicio de las demás prestaciones e indemnizaciones a que hubiere lugar de acuerdo con el Código Sustantivo del Trabajo y demás normas que lo modifiquen, adicionen, complementen o aclaren (Sentencia T-1046/08, M.P. Dr. Mauricio González Cuervo).

Ley 776 de 2002, Art. 8: Contempla la reubicación del trabajador, en términos muy similares a los establecidos en el Decreto 2351 de 1965, antes mencionado, "Los empleadores están obligados a ubicar al trabajador incapacitado parcialmente en el cargo que desempeñaba o a proporcionarle un trabajo compatible con sus capacidades y aptitudes, para lo cual deberán efectuar los movimientos de personal que sean necesarios".

Constitución Política de Colombia, artículo 13: El Estado protegerá especialmente a aquellas personas que por su condición económica, física o mental, se encuentren en circunstancia de debilidad manifiesta y sancionará los abusos o maltratos que contra ellas se cometan. Tal categoría se extiende a todas aquellas personas que, por condiciones físicas de diversa índole, o por la concurrencia de condiciones físicas, mentales y/o económicas, se encuentren en una situación de debilidad manifiesta (C. Const. Sentencia T-1040/01, M.P. Rodrigo Escobar Gil).

En materia laboral, la protección especial de quienes por su condición física están en circunstancia de debilidad manifiesta se extiende también a las personas respecto de las cuales esté probado que su situación de salud les impide o dificulta sustancialmente el desempeño de sus labores en las condiciones regulares, sin necesidad de que exista una calificación previa que acredite su condición de discapacitados (C. Const. Sentencia T-1040/01, M.P. Rodrigo Escobar Gil). 


\section{DERECHO DE REUBICACIÓN EN EL EMPLEO}

De acuerdo a lo expresado por la Corte Constitucional, en la misma sentencia antes citada, el alcance del derecho a ser reubicado por condiciones de salud tiene alcances diferentes dependiendo del ámbito en el cual opera el derecho. Para tales efectos resultan determinantes al menos tres aspectos que se relacionan entre sí:

1) El tipo de función que desempeña el trabajador,

2) La naturaleza jurídica y

3) La capacidad del empleador.

Teniendo en cuenta que, si la reubicación desborda la capacidad del empleador, o si impide o dificulta excesivamente el desarrollo de su actividad o la prestación del servicio a su cargo, el derecho a ser reubicado debe ceder ante el interés legítimo del empleador. Sin embargo, este tiene la obligación de poner tal hecho en conocimiento del trabajador, dándole además la oportunidad de proponer soluciones razonables a la situación.

Todo lo anteriormente enunciado, muy ligado al principio de protección al trabajo, que es sin duda el más importante en cuanto a matriz de los demás, informa que las instituciones de la materia se fundan en la idea de proteger al trabajador considerando las desigualdades que afectan la relación existente entre él y su empleador, manifestada en la tutela debida al trabajo (Conti, 2008, p. 31).

\section{DEFINICIÓN DE DISCAPACIDAD E INVALIDEZ}

Para definir qué es discapacidad e invalidez, optamos por las escogidas por el doctor Rafael Rodríguez Mesa (2016, p. 115), que son del siguiente tenor:

- Discapacidad: Término genérico que incluye limitaciones en la realización de una actividad.

- Invalidez: Es la pérdida de la capacidad laboral u ocupacional igual o superior al cincuenta por ciento (50\%).

\section{DIFERENCIA ENTRE DISCAPACIDAD E INVALIDEZ}

La Corte Constitucional estableció la diferencia entre discapacidad e invalidez por cuanto "podría afirmarse que la discapacidad es el género, mientras que la invalidez es la especie, y en consecuencia no siempre que existe discapacidad necesariamente nos encontramos frente a una persona inválida. La invalidez sería el producto de una discapacidad severa". Así mismo, se 
indicó que la discapacidad "implica una restricción debida a la deficiencia de la facultad de realizar una actividad en la forma y dentro del margen que se considera normal para el ser humano en su contexto social. En este sentido, discapacidad no puede asimilarse, necesariamente a pérdida de capacidad laboral. Así, personas con un algún grado discapacidad pueden desarrollarse plenamente en el campo laboral" (C. Const. Sala Plena, Sentencia T-057/16, M.P. Jorge Ignacio Pretelt Chaljub).

\section{CONCLUSIONES}

La Constitución Política de 1991, que consagró a Colombia como un Estado Social de Derecho, dispuso en los artículos 13, 47, 53, 54 y 68, garantías para todos los ciudadanos que padezcan alguna limitación física, fisiológica, síquica o sensorial, con el fin de que no sean tratados con ningún tipo de discriminación por motivo de la condición debida a su estado de salud para que se logre su integración social y su realización personal, por lo que el legislador, disponiendo de su capacidad configurativa redactó y expidió para su cumplimiento la Ley 361 de 1997, que establece en su artículo 26, que el empleador deberá contar con el permiso del Inspector del Trabajo para efectuar el despido o dar por terminado el contrato de trabajo de su empleado so pena de que se configure un despido sin justa causa y hace acreedor al empleador de la obligación de pagar una indemnización equivalente a ciento ochenta días de salario.

Sin embargo, cabe aclarar que la Corte Constitucional ha expresado, que a pesar de que la estabilidad laboral no es un derecho absoluto, cuando uno de los extremos de la relación laboral está compuesto por un sujeto para quien el constituyente ha consagrado un deber especial de protección, el derecho a la estabilidad laboral adquiere el carácter de fundamental.

Aún nuestra jurisprudencia se queda corta en esta materia, y a diario nos encontramos con casos de trabajadores que en la ejecución de alguna obra sufren accidentes, y al tener contrato de obra-labor, muchas veces son despedidos al darse su finalización, lo que les dificulta poder acceder a un nuevo empleo.

\section{REFERENCIAS BIBLIOGRÁFICAS}

Alexy, R. (2007). Teoría de los derechos fundamentales. Madrid: Trotta.

Canón, L. (2013). La seguridad social en la Constitución colombiana. Bogotá: Universidad Externado de Colombia.

Cepeda, M. (2008). Polémicas constitucionales. Bogotá: Legis. 
Conti, A. (2008). Los principios del derecho del trabajo y su dimensión democrática. Bogotá: Universidad Externado de Colombia.

Colombia. Decreto de 1965. Bogotá: Editorial Legis.

Colombia. Ley 82 de 1988. Bogotá: Editorial Leyer.

Colombia. Decreto de 1989. Bogotá: Editorial Leyer.

Colombia. Decreto 2177 de 1989. Bogotá: Editorial Leyer.

Colombia. Constitución Política Nacional de 1991. Bogotá: Editorial Leyer.

Colombia. Ley 100 de 1993. Bogotá: Editorial Leyer.

Colombia. Ley 361 de 1997. Bogotá: Editorial Leyer.

Colombia. Decreto Ley 2663 de 1950. Bogotá: Editorial Leyer.

Colombia. Ley 776 de 2002. Bogotá: Editorial Legis.

Colombia. Decreto 019 de 2012. Bogotá: Editorial Leyer.

Colombia. Decreto 2351 de 1965. Bogotá: Editorial Legis

Colombia. Corte Constitucional. Sentencia T-462 de 1992, M.P. Gloria Stella Ortiz Delgado. Recuperado de. http://www.corteconstitucional.gov.co/ relatoria/1992/T-462-92.htm

Colombia. Corte Constitucional. Sentencia SU-256 de 1996, M.P. Vladimiro Naranjo Mesa. Recuperado de: http://www.corteconstitucional.gov.co/ relatoria/1996/SU256-96.htm

Colombia. Corte Constitucional. Sentencia C-710 de 1996, M.P. Jorge Arango Mejía. Recuperado de: http://www.corteconstitucional.gov.co/ relatoria/1996/C-710-96.htm

Colombia. Corte Constitucional. Sentencia SU-250 de 1998, M.P. Alejandro Martínez Caballero. Recuperado de. http://www.corteconstitucional. gov.co/relatoria/1998/SU250-98.htm

Colombia. Corte Constitucional. Sentencia C-531 de 2000, M.P. Álvaro Tafur Galvis. Recuperado de. http://www.corteconstitucional.gov.co/relato$\mathrm{ria} / 2000 / \mathrm{C}-531-00 . \mathrm{htm}$

Colombia. Corte Constitucional. Sentencia T-1040 de 2001, M.P. Rodrigo Escobar Gil. Recuperado de: http://www.corteconstitucional.gov.co/ relatoria/2001/t-1040-01.htm

Colombia. Corte Constitucional. Sentencia SU-388 de 2005, M.P. Clara Inés Vargas Hernández. Recuperado de: http://www.corteconstitucional. gov.co/RELATORIA/2005/SU388-05.htm

Colombia. Corte Constitucional. Sentencia T-309 de 2005, M.P. Jaime Córdoba Triviño. Recuperado de: http://www.corteconstitucional.gov. co/relatoria/2006/T-309-06.htm

Colombia. Corte Constitucional. Sentencia T-661 de 2006, M.P. Álvaro Tafur Galvis. Recuperado de: http://www.corteconstitucional.gov.co/relatoria/2006/T-661-06.htm

Colombia. Corte Constitucional. Sentencia T-687 de 2006, M.P. Jaime Córdoba Triviño. Recuperado de: http://www.corteconstitucional.gov. co/relatoria/2006/T-687-06.htm

Colombia. Corte Constitucional. Sentencia T-1046 de 2008, M.P. Mauricio González Cuervo. Recuperado de: http://www.corteconstitucional.gov. 
co/relatoria/2008/T-1046-08.htm

Colombia. Corte Constitucional. Sentencia T-337 de 2009, M.P. Luis Ernesto Vargas Silva. Recuperado de: http://www.corteconstitucional.gov.co/ relatoria/2009/T-337-09.htm

Colombia. Corte Constitucional. Sentencia T-057 de 2016, M.P. Jorge Ignacio Pretelt Chaljub. Recuperado de: http://www.corteconstitucional.gov.co/ relatoria/2016/T-057-16.htm

Colombia. Corte Constitucional. Sentencia T-141 de 2016, M.P. Alejandro Linares Cantillo. Recuperado de. http://www.corteconstitucional.gov.co/ relatoria/2016/T-141-16.htm

Dueñas, O. (2012). Constitucionalización e internacionalización de los derechos a la salud y a la pensión. Bogotá: Universidad del Rosario.

Grisolia, A. (2002). Derecho del trabajo y de la seguridad social. Buenos Aires: Depalma.

Méndez, J. (2016). Derecho laboral, seguridad social y la empresa. La estabilidad laboral reforzada desde la protección de la salud, un desarrollo constitucional. Chile: Biblioteca Jurídica Diké.

Rodríguez, R. (2016). Sistema general de riesgos laborales. Barranquilla: Universidad del Norte.

Valencia, H. (2007). Nomoárquica, principialística jurídica o filosofía y ciencia de los principios generales del derecho. Medellín: Comlibros.

Vanegas, A. (2007). Diccionario de derecho individual del trabajo. Bogotá: Legislación-jurisprudencia-doctrina.

Villegas, J. (2016). Derecho Administrativo Laboral. Principios, estructura y relaciones individuales. Tomo I. Bogotá: Legis.

Zagrebelsky, G. (1995). El derecho dúctil. Ley, derechos, justicia. Madrid: Trotta. trad. de Marina Gascón. 